\title{
Dampak Pencemaran Lingkungan dan Eksploitasi Sumber Daya Alam: Beberapa Pandangan Al-Quran
}

\author{
Kamarudin Kamarudin ${ }^{1}$, Ahmad Sehri ${ }^{2}$, Juhrah M. Arib ${ }^{3}$, Muhammad Hasdin Has ${ }^{4}$, \\ Sabil Mokodenseho ${ }^{5}$ \\ ${ }^{1}$ Institut Agama Islam Negeri Datokrama Palu, Indonesia \\ Email: kamarudin170767@gmail.com \\ ${ }^{2}$ Institut Agama Islam Negeri Datokrama Palu, Indonesia \\ Email: ahmadsehhri@gmail.com \\ ${ }^{3}$ Institut Agama Islam Negeri Manado, Indonesia \\ Email: aribjuhrah@gmail.com \\ ${ }^{4}$ Institut Agama Islam Negeri Kendari, Indonesia \\ Email: mrhas98@gmail.com \\ ${ }^{5}$ Universitas Islam Negeri Syarif Hidayatullah Jakarta, Indonesia \\ Email: sabil.mokodenseho@gmail.com
}

\begin{abstract}
Islam has discussed a lot of ways to treat the environmentand properly utilize natural resources. In fact, the Quran warns humans on the effects or consequences arising from the excessive use of natural resources. This article tries to provide Qur'anic views on the effects of environmental pollution and excessive exploitation of resources. Any human that pollutes the environment and misuses it, is punishable by God in this world and hereafter. Natural resources such as land, water, animals, and plants need to be maintained and properly managed as a form of gratitude and devotion to God. This research concludes that environmental preservation and adequate use of natural resources is an obligation for every human being, especially for Muslims. Therefore, every human being needs to protect the environment and make a balance in using natural products.
\end{abstract}

Keywords: Environment; Exploitation; Natural resources; the view of the Quran

\section{Pendahuluan}

Al-Quran sebagai pedoman umat Islam tidak hanya menginformasikan dan mengatur berbagai hal yang berkaitan dengan masalah ibadah [1-2], tetapi menyangkut juga berbagai aspek kehidupan lain seperti menjaga dan melestarikan lingkungan atau alam semesta (bumi) [3-4], termasuk pengelolaan sumber daya alam yang dimilikinya (QS. al-Qashash: 77). Literatur Islam lainnya yang banyak membahas terkait masalah ini adalah hadis Rasulullah SAW, selain fikih lingkungan sebagai produk ijtihad para ulama atau intelektual Islam [5-6]. Teknis pengelolaan lingkungan yang diinformasikan alQuran dinyatakan dalam hadis-hadis Rasulullah, baik yang berkenan dengan anjuran menjaga dan memelihara lingkungan, memanfaatkan lingkungan serta pencegahan kerusakan lingkungan. Misalnya, larangan meggunakan sumber daya alam secara berlebihan sekalipun untuk urusan ibadah "Dari Aisya r.a. bahwa Rasulullah SAW mandi dengan air sebanyak satu sha (gantang) dan berwudhu dengan air sebanyak satu mud" (HR. Abu Daud). Hadis tersebut menjadi bukti bahwa Islam memberi perhatian penuh soal bagaimana seharusnya sikap dan tindakan manusia menggunakan sumber daya alam, utamanya menekankan pentingnya menjaga pelestarian sumber daya alam secara moral [7]. Berbagai hal dasar seperti air, tanah, udara terbuka untuk semua orang karena pada dasarnya alam memang disiapkan untuk manusia [8-9]. Namun, Islam mewajibkan umatnya untuk menjaga dan memelihara alam atau lingkungan [10-11] dari perbuatan-perbuatan dosa yang dalam arti merusak lingkungan dan penggunaan sumber daya alam secara berlebihan [12].

Banyak fakta kerusakan pada lingkungan terjadi karena pengelolaan manusia yang kurang tepat. Zmami dan Ben-Salha meneliti faktor-faktor penentu degradasi lingkungan di negara-negara Gulf 
Cooperation Council (GCC), yakni Kuwait, Oman, Bahrain, Qatar, Arab Saudi, dan Uni Emirat Arab, antara tahun 1980 dan 2017. Hasil penelitian mereka mengemukakan bahwa konsumsi energi dan investasi asing langsung menyebabkan lebih banyak degradasi lingkungan dalam jangka panjang [13]. Dari pendekatan lain, Wang, Gao, Li, dan Feng mencoba mengintegrasikan komponen-komponen demografis, spasial, ekonomi dan sosial, serta membagi 190 negara menjadi 4 subpanel sesuai dengan tingkat pendapatan nasional, untuk mengidentifikasi efek heterogenitas urbanisasi terhadap polutan PM2.5 untuk periode 1998-2014 dari perspektif global. Salah satu hasil penelitan mereka mengungkapkan bahwa urbanisasi spasial telah memberikan efek negatif pada polusi udara di negaranegara berpenghasilan tinggi [14]. Peningkatan polusi udara juga terjadi di Indonesia sejak tahun 1990. Shao, Miller dan Jin mengatakan Indonesia menempati peringkat 20 besar negara paling tercemar [15], dan ada 52.000 kematian prematur dari polusi udara pada tahun 2017, sama dengan sepertiga dari semua kematian yang disebabkan oleh polusi udara luar ruangan di Asia Tenggara pada tahun 2017 sebagaimana laporan Health Effects Institute (2019) [16].Terkait dengan polusi udara tersebut, Greenstone dan Fan menemukan bahwa hilangnya harapan hidup karena kualitas udara yang memburuk rata-rata sekitar 1,2 tahun di Indonesia [17].

Berdasarkan penelitian di atas, maka sudah seharusnya manusia menjaga agar lingkungan tidak tercemar dan menggunakan sumber daya alam secara bijaksana. Artinya penggunaan sumber daya alam tidak melebihi apa yang memang menjadi kebutuhan manusia. Islam sebagai sumber ajaran banyak menyinggung soal bagaimana memperlakukan lingkungan dengan baik, juga soal bagaimana sumber daya alam digunakan. Bahkan, Al-Quran telah banyak memberi peringatan kepada manusia soal dampak atau akibat yang ditimbulkan dari pemanfaatan sumber daya alam secara berlebihan. Oleh karena itu, artikel ini mencoba memberikan beberapa pandangan Al-Quran tentang dampak pencemaran lingkungan dan pemanfaatan sumber daya secara berlebihan untuk diketahui, dipahami dan dipraktekkan dalam kehidupan.

\section{Hasil dan Pembahasan}

\subsection{Manusia dan Alam Semesta (Lingkungan Hidup)}

Hubungan antara manusia dengan alam atau hubungan manusia dengan sesamanya [18], bukan merupakan hubungan antara penakluk dan yang ditaklukkan, atau antara Tuhan dengan hamba, tetapi hubungan kebersamaan dalam ketundukan kepada Allah SWT [19]. Manusia diperintahkan untuk memerankan fungsi kekhalifahannya, yaitu kepedulian, pelestarian dan pemeliharaan [20]. Berbuat adil dan tidak bertindak sewenang-wenang kepada sesama makhluk sehingga hubungan yang selaras antara manusia dan alam mampu memberikan dampak positif bagi keduanya [21]. Oleh karena itu, manusia diperintahkan untuk mempelajari dan mengembangkan pengetahuan alam guna menjaga keseimbangan alam dan meningkatkan keimanan sebagai bentuk rasa syukur kepada Allah SWT.

Lingkungan berarti semua hal yang ada di sekitar kita, baik manusia, hewan, tumbuhan, dan semua hal lainnya [22]. Ladang dan rumput hijau di pedesaan [23], serta kendaraan [24], pabrikpabrik, bangunan kantor dan mall di perkotaan [25], juga merupakan bagian dari lingkungan. Lingkungan yang seimbang adalah berkat terbesar dari Allah SWT. Tuhan telah mengatur semua kebutuhan di bumi dengan cara yang sangat mengesankan, tetapi biasanya manusia sedikit dalam hal mensyukurinya (QS. al-A'raf: 10). Hal-hal yang diperlukan untuk keindahan lingkungan disebutkan dalam al-Quran bahwa Allah membentangkan bumi dan menjadikan gunung-gunung dan sungaisungai padanya. Allah yang membuat buah-buahan berpasang-pasangan, dan menutupkan malam kepada siang. Dari sini manusia sebagai makhluk yang berfikir dapat melihat betapa besar kekuasaan Allah (QS. al-Ra'd: 3-4). Hubungan manusia dengan bumi (lingkungan hidup) itu erat kaitannya, di 
mana bumi, baik menjadi tempat bagi manusia yang hidup maupun yang telah mati (QS. al-Mursalat: 25-26). Hanya Allah yang menciptakan semua yang ada di bumi, seperti tumbuhan, hewan dan lain sebagainya, untuk keperluan manusia (QS. al-Baqarah: 29).

Tuhan telah memberikan manusia segala potensi [26] yang salah satunya adalah mengelola lingkungan sesuai dengan kebutuhannya [27]. Potensi yang ada harus diarahkan pada perbaikan dan kerja-kerja yang positif, yang dalam konteks ini perbaikan lingkungan hidup. Namun, manusia kerapkali menganggap remeh soal ini, di mana masih banyak yang menggunakan energi secara berlebihan, mengeksploitasi sumber daya alam, membuang sampah bukan pada tempatnya, hingga penebangan hutan telah menimbulkan ancaman besar bagi lingkungan [28]. Polusi udara, air dan tanah merupakan masalah global hingga saat ini. Perlakuan manusia seperti itu memengaruhi komposisi atmosfer dan iklim global. Ketika manusia tidak menggunakan lingkungannya sesuai dengan ajaran Islam, hasilnya akan berimbas pada munculnya kerusakan, baik di darat maupun di laut yang disebkan oleh tangan manusia itu sendiri (QS. al-Baqarah: 57). Kesewenang-wenangan terhadap lingkungan adalah perbuatan tidak terpuji yang dilakukan secara egois. Ketika manusia melakukan hal itu sebenarnya mereka melukai dan menyakiti dirinya sendiri (QS. an-Nahl: 33).

Ada beberapa tindakan manusia yang mengancam lingkungan serta pengelolaan sumber daya alam yang kurang tepat, di antaranya: Pertama, penggunaan energi dan sumber daya secara berlebihan [29]. Energi diperlukan dalam produksi, transportasi, dan rumah tangga. Namun, banyak energi yang bisa melakukan pekerjaan bermanfaat terbuang sia-sia oleh manusia. Misalnya, alih-alih menggunakan transportasi umum, mobil pribadi yang digunakan menghabiskan banyak bahan bakar. Demikian pula peralatan rumah tangga dibiarkan berjalan, bahkan ketika tidak ada yang menggunakannya. Kedua, penipisan sumber daya [30]. Sumber daya adalah hal-hal di lingkungan yang siap digunakan manusia atau dapat digunakan di masa depan. Minyak dan batubara adalah sumber daya seperti halnya mineral, hewan dan pohon. Semua sumber daya di bumi terbatas dan banyak di antaranya seperti mineral dan bahan bakar fosil, tidak dapat diperbarui. Jadi, sumber daya tersebut dapat habis segera jika penggunaannya yang tidak bijaksana, tidak diatur pemakaiannya dan tidak mereka lestarikan.

Ketiga, industrialisasi [31]. Peningkatan produksi adalah keharusan untuk mendapatkan fasilitas kehidupan yang lebih baik. Untuk tujuan ini manusia telah mempopulerkan industri. Energi diperoleh dari bahan bakar fosil, banyak bahan kimia juga digunakan. Asap, air yang tercemar, limbah dan lainnya dari pabrik adalah sumber utama degradasi lingkungan. Keempat, urbanisasi [32]. Daya tarik dan fasilitas yang lebih baik, serta kondisi kehidupan membuat orang lebih memilih menetap di kota dibandingankan tinggal di desa. Karena mengikuti gaya tersebut, banyak masalah meningkat setiap harinya, seperti meningkatnya jumlah kendaraan di jalan, polusi debu dan asap kendaraan, lebih banyak rumah dibutuhkan, tanah pertanian yang berguna digunakan untuk koloni perumahan, limbah rumah tangga dan industri menyebabkan polusi udara, air dan tanah.

Kelima, penipisan lapisan ozon [33]. Ozon adalah gas yang hadir dalam bentuk amplop di sekitar bumi di atmosfer bagian atas. Lapisan ini mencegah radiasi ultra-violet dari matahari untuk mencapai bumi. Klorofluorokarbon dilepaskan dari lemari es, AC dan kaleng semprotan. Zat kimia ini bereaksi dengan ozon dan menyebabkan penipisan dan penghancuran lapisan ozon. Akibatnya, radiasi ultraviolet dapat mencapai bumi. Radiasi dapat menyebabkan penyakit mata dan kanker. Keenam, efek rumah kaca dan pemanasan global [34]. Radiasi yang datang dari matahari bisa masuk ke selang hijau, tetapi gelombang panas yang memiliki panjang gelombang lebih lama, tidak bisa keluar darinya. Ini menghasilkan peningkatan suhu rumah kaca. Karena industrialisasi, proporsi beberapa gas di udara seperti karbon dioksida, klorofluorokarbon dan metana telah meningkat. Kehadiran gas-gas ini di 
udara dalam proporsi yang lebih tinggi menghasilkan efek rumah kaca. Karena efek tersebut, suhu bumi meningkat sehingga terjadi pemanasan global.

Ketujuh, pertanian mekanis [35]. Pertanian dengan mesin atau memanfaatkan mesin, pupuk dan pestisida. Tidak diragukan lagi, ini meningkatkan produksi tanaman dan makanan, tetapi pada saat yang sama telah memperdalam masalah lingkungan. Kedelapan, deforestasi [36]. Hutan adalah kekayaan besar kita dan penting dalam membawa perubahan iklim, menghentikan badai dan membawa hujan. Hutan mencegah erosi tanah, dan menyediakan habitat bagi berbagai macam kehidupan liar. Deforestasi memiliki banyak efek buruk terhadap lingkungan karena habitat satwa liar dihancurkan, meyebabkan terjadinya perubahan iklim dan cuaca, serta keadaan tanah tidak subur lagi.

Allah telah menciptakan makhluk hidup di bumi dan memberi manusia keunggulan dari pada makhluk hidup lainnya, termasuk hewan. Allah telah menciptakan lingkungan untuk keselamatan dan manfaat manusia. Setiap makhluk hidup memiliki peran tertentu di dalamnya. Manusia dan hewan keduanya adalah makhluk hidup. Hewan memainkan peran penting dalam lingkungan. Hewan diperlukan untuk memenuhi persyaratan manusia dan lingkungan. Manusia mendapat daging, kulit, obat-obatan, susu dan madu dari hewan, bahkan hewan digunakan sebagai alat transportasi. Hewan tidak hanya menambah keindahan lingkungan, tetapi juga menjaga standar dan kelayakannya. Tidak bisa dipungkiri, hewan ikut meningkatkan ekonomi manusia dengan menyebarkan benih dan penyerbukan tanaman. Setiap binatang yang bergerak di muka bumi, dan burung yang terbang di langit adalah komunitas seperti manusia (QS. al-An'am: 38).

Tuhan telah menyebutkan dalam al-Quran tentang pertumbuhan dan keselamatan hewan. Diciptakannya hewan seperti sapi, unta dan domba adalah untuk manusia yang sebagian bisa ditunggangi dan sebagian yang lain untuk dimakan dagingnya (QS. al-Mukmin: 79). Daging hewan adalah unsur makanan manusia yang lezat dan bergizi seperti yang dibahas dalam al-Quran. Ini mengartikan bahwa manusia dan hewan saling membutuhkan dalam beberapa hal. Allah telah menyebutkan bahwa semua makhluk hidup dan tidak hidup tunduk di hadapan-Nya dengan patuh, baik yang ada di langit maupun di bumi seperti matahari, bulan, bintang, gunung, pohon-pohon, binatang dan manusia. Banyak di antara mereka yang telah menerima siksaan, dan siapa pun yang dipermalukan Allah, tidak ada yang dapat memberinya kehormatan (QS. al-Hajj: 18). Karena hewan memiliki banyak manfaat, maka Rasulullah SAW menolak untuk melukai mereka dengan cara ilegal dan tidak wajar. Rasulullah SAW mengatakan bahwa adalah benar-benar melanggar hukum membunuh hewan dengan mengikatnya. Menghukum binatang dengan api hanyalah pekerjaan Allah.

\subsection{Prinsip Pengelolaan Sumber Daya Alam dalam Al-Quran}

Al-Quran menjelaskan bahwa bumi dan seisinya hakikatnya diciptakan Allah SWT untuk manusia (QS. al-Baqarah: 29). Semua yang ada di langit dan bumi, matahari dan bulan, malam dan siang, daratan dan lautan, binatang melata dan binatang ternak, serta tanaman dan buah-buahan semuanya diciptakan untuk kemaslahatan dan kebahagiaan hidup manusia (QS. al-An'am: 141). Segala sesuatu yang ada di muka bumi ini diserahkan kepada manusia sehingga manusia dijadikan sebagai khalifah di muka bumi (QS. al-Baqarah: 30), dan memegang tanggungjawab mengelola bumi dan memakmurkannya (QS. al-Ahzab: 72). Sebagai khalifah di muka bumi, manusia diperintahkan beribadah kepada-Nya dan diperintah berbuat kebajikan dan dilarang berbuat kerusakan (QS. alQasas: 77). Berdasarkan beberapa ayat al-Quran tersebut, maka kaitannya dalam berinteraksi dan memanfaatkan alam serta lingkungan hidup itu, manusia secara umum mengemban tiga amanat dari Allah [37]. Pertama, al-i'tibar, manusia dituntut untuk senantiasa memikirkan dan menggali rahasia di balik ciptaan Allah SWT seraya dapat mengambil pelajaran dari berbagai kejadian dan peristiwa alam. 
Kedua, al-islah, manusia diwajibkan untuk terus menjaga dan memelihara kelestarian lingkungan itu. Ketiga, al-intifa', manusia mengambil manfaat dan mendayagunakan hasil alam dengan sebaikbaiknya demi kesejahteraan dan kemaslahatan. Allah SWT telah memberikan fasilitas daya dukung lingkungan bagi kehidupan manusia [38-39].

Agar manusia dapat membiasakan diri ramah terhadap lingkungan, diperlukan beberapa prinsip kaitannya dengan perilaku manusia dalam memperlakukan alam [40], yakni; prinsip menghormati alam. Dalam al-Quran, manusia diutus melainkan hanya untuk rahmat bagi alam semesta (QS. alAnbiya: 107); rahmat bagi alam semesta bukan hanya sekedar dijadikan sebagai motto Islam, akan tetapi justru merupakan tujuan dari Islam itu sendiri; prinsip tanggung jawab. Kaitanya dengan prinsip hormat terhadap alam sebagaimana disebutkan di awal merupakan tanggung jawab pelaku moral terhadap alam karena manusia diciptakan sebagai khalifah di muka bumi; prinsip solidaritas, yang terkait dengan dua prinsip moral tersebut adalah prinsip solidaritas; dan terakhir adalah prinsip kasih sayang dan kepedulian terhadap alam [41-43]. Dengan demikian, manusia memiliki peranan sangat penting dalam pemanfaatan sumber daya alam.

\subsection{Pencemaran Lingkungan dan Dampaknya terhadap Makhluk Hidup}

\subsubsection{Pencemaran Tanah}

Pencemaran tanah adalah keadaan di mana bahan-bahan kimia buatan manusia masuk dan mengubah lingkungan tanah alami. Ketika suatu zat berbahaya masuk ke dalam tanah, maka ia dapat menguap tersapu air hujan dan atau masuk ke dalam tanah [44]. Kebanyakan penyebab polusi tanah adalah limbah yang merupakan hasil dari aktivitas manusia. Limbah umumnya terdiri dari sampah, limbah industri, limbah konstruksi, limbah pertambangan, dan sebagainya. Unsur kimia terdiri dari pestisida, herbisida, fungisida dan insektisida [45]. Ini semua bahan kimia yang meskipun memberikan beberapa manfaat, tetapi ini sepenuhnya berbahaya bagi tanah. Misalnya, penggunaan pestisida pertanian yang mengandung beberapa bahan berbahaya seperti arsenik, hidrokarbon terklorinasi, hormon, karbonat, antikoagulan dan organofosfat [46]. Senyawa tersebut merusak sistem mental dan persepsi [47]. Tanah yang tercemar dapat memengaruhi kelangsungan hidup manusia, dan makhluk lain, serta lingkungan di mana makhluk hidup tinggal. Tanah dalam kaitannya dengan pandangan al-Quran, sejatinya telah diingatkan dalam beberapa ayat tentang bagaimana pentingnya tanah itu bagi manusia dan sebagainya [48] Tanah diciptakan Allah untuk manusia dan makhluk lainnya (QS. ar-Rahman: 10). Seperti halnya udara dan air, tanah juga diperlukan untuk kelangsungan hidup. Pada dasarnya manusia diciptakan dari tanah dan kemudian berkembang biak di dunia (QS. ar-Rum: 20). Tanah adalah tempat manusia hidup dan menjadi tempat untuk manusia kembali atau mati (QS. Nuh: 17-18; QS. al-Mursalat: 2526). Oleh karenanya, tanah harus juga dikelola dan diberdayakan dengan sebaik-baiknya agar tidak terjadi pencemaran tanah.

Meskipun demikian jelasnya dalam al-Quran sebagaimana di atas, masih banyak di antara manusia yang tidak mengindahkannya. Ini kemudian yang menjadi persoalan besar dikemudian hari yang berdampak langsung kepada kehidupan makhluk hidup, utamanya dari segi kesehatan dan kebersihan [49]. Di mana pada dasarnya manusia menyukai kebersihan dan lingkungan yang segar sebagaimana Allah juga menyukai orang-orang yang bersih dan suci (QS. al-Taubah: 108). Kebersihan adalah kebalikan dari sampah dan kotoran. Sehingga itu, tidak ada manusia yang suka dengan hal-hal yang kotor karena itu adalah tempat tinggal nyamuk dan serangga [50]. Mereka menyebarkan kuman dan penyakit di rumah dan tempat tinggal. Dengan demikian, penggunaan hal-hal sebagaimana disebutkan di awal, yang menjadi pemicu kerusakan lingkungan dan mengganggu kelangsungan hidup semua makhluk. Untuk itu, penggunaannya harus segera diminimalisir, mengingat bahaya langsung 
yang berdampak bagi makluk hidup dan lingkungan yang ada. Dan hal itu jelas bertentangan dengan maksud Tuhan sebagaimana dalam al-Quran yang sudah dijelaskan di atas.

\subsubsection{Pencemaran Air}

Air merupakan hadiah yang banyak manfaat untuk makhluk hidup. Tanpa air, hidup adalah hal yang mustahil. Dari air Allah menjadikan segala sesuatu yang hidup (QS. al-Anbiya: 30), dan memelihara varietas di alam semesta. Dari air yang sama pula, banyak hal yang berbeda muncul dari bumi, baik itu warna, rasa dan bentuk. Kaitanya dengan pertumbuhan tanaman, Allah turunkan air dari langit untuk menghidupkan kembali bumi sesudah mati atau kering (QS. al-Baqarah: 164). Air yang membuat berbagai macam tumbuh hidup subur dan menghijau (QS. al-An'am: 99). Dalam potongan ayat yang lain Allah menyuruh manusia untuk melihat bahwa ketika bumi ini kering, kemudian diturunkannya hujan, maka hidup suburlah bumi ini dengan berbagai macam tumbuhan yang indah. (QS. al-Hajj: 5). Dengan demikian, kita harus menjaga apa yang diberikan Tuhan dengan sebaik-baiknya.

Polusi air adalah perubahan keadaan di tempat penampungan air seperti danau, sungai, lautan dan air tanah akibat aktivitas manusia, berupa mengotorinya melalui kotoran dan limbah beracun dan bahan kimia [51]. Ketika air tidak dapat digunakan, itu disebut air tercemar, sedangkan perubahan fisik dan kimia air disebut polusi yang efeknya sangat buruk bagi kehidupan. Ada banyak alasan terjadinya pencemaran air, yakni adanya bahan limbah industri, obat-obatan kimia, bahan kimia, limbah manusia dan hewan, emisi cairan sebagai minyak bumi dan produk-produknya, limbah atom dan lain sebagainya [52]. Sementara efeknya adalah ketika air yang tercemar melewati bumi ke lapisan bawahnya, itu mencemari sungai dan kanal. Karena itu, kehidupan air berdampak buruk. Berbagai bahan kimia memanaskan air dan mengurangi jumlah oksigen yang diperlukan makhluk hidup.

\subsubsection{Pencemaran Udara}

Elemen-elemen yang mengesankan polusi udara disebut polutan. Ini disebut polutan primer dan polutan sekunder. Polusi udara disebabkan oleh beberapa hal, yakni kendaraan, karbon monoksida, sulfur dioksida, karbon klorofluoro, nitrogen oksida, hidrokarbon, bahan-bahan industri, merokok, penggunaan bahan bakar, limbah sisa padat, dan sebagainya [53]. Efek polusi udara menyebabkan banyak penyakit seperti gangguan pernapasan, jantung, amandel dan sebagainya. World Health Organization (WHO) mengatakan setiap tahun ada 4,6 juta orang meninggal karena polusi udara [54]. Al-Quran mengingatkan bahwa berbagai kerusakan atau bencana yang terjadi merupakan ulah tangan manusia (QS. ar-Rum: 41). Karena hanya manusia yang memiliki inisiatif dan daya kreatif, sehingga diberi tugas sebagai wakil Allah di bumi, sedangkan makhluk lain hanya mempunyai tabiat dan insting yang abadi. Melalui semua itu, manusia menciptakan berbagai teknologi modern, membangun gedung-gedung yang besar dan mewah, membangun jembatan dan jalan raya, dan sebagainya. Namun, ada juga manusia yang membuat bom, membakar hutan, mencemari sungai dengan limbah, dan lainlain. Kalau kita cermati ayat tersebut, pernyataan Allah menunjukkan bahwa kerusakan itu sifatnya insidentan sifatnya. Sebelum ada manusia tidak ada kerusakan, namun setelah kehadiran manusia barulah timbul kerusakan di darat maupun di laut.

Beberapa hal yang perlu diketahui bahwa kerusakan pada lingkungan dapat berupa penebangan hutan, pencemaran, perubahan iklim, pemanasan global dan perusakan ozon [55]. Iklim sedang tercemar oleh asap kendaraan dan pabrik. Kehidupan liar berada dalam bahaya karena deforestasi. Limbah domestik dan limbah industri dibuang ke sungai dan badan air lain tanpa mengolahnya. Hal tersebut membuat air yang awalnya bersih menjadi tidak layak untuk digunakan oleh manusia dalam 
kehidupan sehari-hari. Hutan ditebangi untuk mendapatkan kayu bakar dan ruang. Tidak bijaksana dan pemanfaatan sumber daya yang berlebihan adalah penyebab utama degradasi lingkungan. Suhu tanah terus meningkat karena efek rumah kaca. Perlu diingat bahwa penyebab utama kerusakan lingkungan adalah manusia dan aktivitasnya. Manusia menggunakan sumber daya yang ada secara berlebihan untuk mendapatkan ketenangan dan kepuasaan.

Allah SWT telah memberikan peringatan kepada kita lewat al-Quran untuk menjaga dan melestarikan lingkungan, serta mengelola sumber daya alam dengan sebaik-baiknya. Penelitian ini memberikan beberapa hal terkait bagaimana menjaga lingkungan dan mengelola sumber daya alam dengan baik sesuai dengan nilai-nilai yang terkandung dalam al-Quran, yaitu membuang sampah secara benar, jangan membuang sampah industri dan domestik tanpa pengolahan ke udara, darat dan air; gunakan bahan bakar dalam kendaraan yang menghasilkan polusi paling sedikit; menghemat atau meminimalisir pemanfaatan sumber daya; daur ulang sampah plastik, gelas dan kertas; lebih suka menggunakan angkutan umum daripada mobil pribadi; tanam lebih banyak pohon untuk mencegah tanah longsor dan banjir; serta matikan lampu, AC dan kipas angin saat tidak ada orang di rumah.

\section{Kesimpulan}

Penelitian ini berusaha menyoroti beberapa aspek lingkungan dalam ajaran Islam yang ada dalam alQuran. Berdasarkan pada dalil-dalil al-Quran yang dikemukakan, Islam sangat menekankan pada lingkungan dan sumber daya alam sebagai anugerah Tuhan atas makhluk hidup, terutama air, tanaman, udara dan hewan. Hal-hal tersebut menjadi lingkungan kita, dan makhluk hidup tidak akan lepas daripadanya. Tanah juga merupakan satu-satunya elemen yang merupakan bagian terbesar dari sumber daya alam karena sumber daya yang tidak terhitung jumlahnya tersembunyi di dalamnya. Dengan demikian, menjadi jelas bahwa dalam Islam lingkungan itu memiliki nilai intrinsik. Sekalipun tidak ada ancaman atau kekurangan, kita harus tetap menjaga sumber daya alam, melindungi hewan dan tumbuhan, dan secara umum meningkatkan dan melestarikan lingkungan yang ada. Artikel ini menyimpulkan bahwa menurut Al-Quran manusia harus bijaksana dalam sikap dan tindakan terhadap lingkungannya. Menjaga lingkungan adalah bagian dari menjaga hubungan manusia dengan alam, serta sebagai pengabdian manusia dengan Tuhan. Islam menyediakan model etika lingkungan yang komprehensif di mana pada saat yang sama manusia adalah konsumen dan penerima manfaat dari lingkungan itu sendiri.

\section{Referensi}

[1] A. Unsal 2020 A New Approach to Islamic intellectual tradition Pathways to Contemporary Islam: New Trends in Critical Engagement. 77

[2] M. A. Anwar, A .M. O. Gani, \& M. S. Rahman 2020 Effects of spiritual intelligence from Islamic perspective on emotional intelligence Journal of Islamic Accounting and Business Research.

[3] A. Muhamad, A. H. Syihab, \& A. H. Ibrahim 2020 Preserving human-nature's interaction for sustainability: Quran and Sunnah Perspective Science and Engineering Ethics. 1-14.

[4] B. M. Yunus, M. R. Mohd Nor, H. Khoiruddin, \& N. W. P. Amatillah 2020 Isti 'mār Al-Arḍ: The concept of prosperity for the earth from Qur'ānic perspective International Journal of Psychosocial Rehabilitation. 2404 5102-5116

[5] N. Shah, \& S. Sharma 2020 An environmental aspect of article 21: A judicial approach studies in Indian place names. 4071 1916-1924 
[6] A. Dilay, A. P. Diduck, \& K. Patel 2020 Environmental justice in India: a case study of environmental impact assessment, community engagement and public interest litigation Impact Assessment and Project Appraisal. 381 16-27

[7] K. Singh 2020 Tracing environmental ethics in the HolyQur'an. Studies in Indian Place Names. $4011519-1523$

[8] A. Andriansyah, T. Taufiqurokhman, \& I. S. Wekke 2019 Impact of environmental policy factors on tourism industry: A study from Indonesia over last three decades International Journal of Energy Economics and Policy. 93360

[9] C. Pérez, \& O. Claveria 2020 Natural resources and human development: Evidence from mineral-dependent African countries using exploratory graphical analysis Resources Policy. 65 101535

[10] J. La Fua, R. U. Nurlila, F. Gunawan, \& I. S. Wekke 2018 Islamic education on formation of environmental awareness in Indonesian Islamic Boarding Schools In IOP Conference Series: Earth and Environmental Science. IOP Publishing. 1561012035

[11] S. Kuraedah, F. Gunawan, I. S. Wekke, \& B. Hamuddin 2018 Learning environment construction in Islamic Higher Education: Connecting the puzzles of ideas In IOP Conference Series: Earth and Environmental Science. IOP Publishing. 1751012107

[12] S. Garg 2020 Impact of overpopulation on land use pattern In Environmental and Agricultural Informatics: Concepts, Methodologies, Tools, and Applications. IGI Global. 1517-1534

[13] M. Zmami, \& O. Ben-Salha 2020 An empirical analysis of the determinants of CO2 emissions in GCC countries International Journal of Sustainable Development \& World Ecology. 1-12

[14] S. Wang, S. Gao, S. Li, \& K. Feng 2020 Strategizing the relation between urbanization and air pollution: Empirical evidence from global countries Journal of Cleaner Production. 243118615

[15] Z. Shao, J. Miller, \& L. Jin 2020 Soot-free road transport in Indonesia: A cost-benefit analysis and implications for fuel policy International Council on Clean Transportation. 1-16

[16] Health Effects Institute 2019 State of global air 2019. Data source: Global Burden of Disease Study 2017. Institute for Health Metrics and Evaluation 2018.

[17] M. Greenstone, \& Q. Fan 2019 Indonesia's worsening air quality and its impact on life expectancy AQLI: Air Quality Life Index.

[18] J. Whitburn, W. Linklater, \& W. Abrahamse 2020 Meta-analysis of human connection to nature and proenvironmental behavior Conservation Biology. 341 180-193

[19] P. Smith 2020 The origins of morality: God versus nature Quadrant. 64 1/2 90

[20] R. G. Alvim, M. M. de Oliveira, \& H. G. Castellanos 2020 Global social change: Human ecology from an eco-ethical perspective In Global Changes. Springer, Cham. 121-130

[21] J. Lawson, \& J. Kingsley 2020 The language of Australian human-ecological relationship: identity, place, and landscape Handbook of the Changing World Language Map. 3333-3347

[22] K. M. Osman, A. D. Kappell, E. M. Fox, A. Orabi, \& A. Samir 2020 Prevalence, pathogenicity, virulence, antibiotic resistance, and phylogenetic analysis of biofilm-producing listeria monocytogenes isolated from different ecological niches in Egypt: Food, humans, animals, and environment Pathogens. 915

[23] M. Varol, M. R. Sünbül, H. Aytop, \& C. H. Y1lmaz 2020 Environmental, ecological and health risks of trace elements, and their sources in soils of Harran Plain, Turkey Chemosphere. 245 125592 
[24] S. Kundu, \& U. Maulik 2020 Vehicle pollution detection from images using deep learning In Intelligence Enabled Research. Springer, Singapore. 1-5

[25] T. Kozai, \& G. Niu 2020 Role of the plant factory with artificial lighting (PFAL) in urban areas. In Plant Factory. Academic Press. 7-34

[26] C. Adang 2019 Islam as the inborn religion of mankind: the concept of fițra in the works of Ibn Hazm Al-Qanțara. 212391

[27] H. Khambhaita, \& R. Alami 2020 Viewing robot navigation in human environment as a cooperative activity In Robotics Research. Springer, Cham. 285-300

[28] L. A. Duguma, J. Atela, P. A. Minang, A. N. Ayana, B. Gizachew, J. M. Nzyoka, \& F. Bernard 2019 Deforestation and forest degradation as an environmental behavior: unpacking realities shaping community actions Land. 8226

[29] H. Bohn, \& R. T. Deacon 2000 Ownership risk, investment, and the use of natural resources American Economic Review. 903 526-549

[30] T. Prior, D. Giurco, G. Mudd, L. Mason, \& J. Behrisch 2012 Resource depletion, peak minerals and the implications for sustainable resource management Global environmental change. 223 577-587

[31] E. E. O. Opoku, \& M. K. Boachie 2020 The environmental impact of industrialization and foreign direct investment Energy Policy. 137111178

[32] X. Cui, C. Fang, H. Liu, X. Liu, \& Y. Li 2020 Dynamic simulation of urbanization and ecoenvironment coupling: Current knowledge and future prospects Journal of Geographical Sciences. 302 333-352

[33] S. S. Ningombam, P. Vemareddy, \& H. J. Song 2020 Effect of lower stratospheric temperature on total ozone column (TOC) during the ozone depletion and recovery phases Atmospheric Research. 232104686

[34] C. Albouy, V. Delattre, G. Donati, T. L. Frölicher, S. Albouy-Boyer, M. Rufino, ... \& F. Leprieur 2020 Global vulnerability of marine mammals to global warming Scientific Reports. 101 1-12

[35] F. Saleh, H. Prayuda, F. Monika, \& M. M. A. Pratama 2019 Characteristics comparison on mechanical properties of mortars using agriculture waste as a cement replacement materials In IOP Conference Series: Materials Science and Engineering. IOP Publishing. 6501012039

[36] A. Alesina, C. Gennaioli, \& S. Lovo 2019 Public goods and ethnic diversity: Evidence from deforestation in Indonesia Economica. 86341 32-66

[37] 18 D. Ghernaout 2017 Environmental principles in the Holy Koran and the Sayings of the Prophet Muhammad Am. J. Environ. Prot. 6 75-79

[38] 19 A. Islamy 2019 Dialectic motivation, behavior and spiritual peak experience in the perspective of Islamic psychology Alfuad. 32 35-46

[39] 20 D. Ratnasari 2019 Sheikh Mahfudz at-Tarmasi's thought on islamic education Jurnal Pendidikan Islam. 81 95-119

[40] 21 N. Kholis, \& N. Mufidah 2020 Community multicultural integration pattern in environmentbased learning International Journal of Instruction. 131

[41] 22 T. V. Kumar 2020 Smart Environment for Smart Cities In Smart Environment for Smart Cities. Springer, Singapore. 1-53 
[42] 23 A. Hadi, P. Yanita, C. F. B. Hartanto, \& S. N. Sychanina 2020 Strategic environment resource management concept and needs Journal of Environmental Treatment Techniques. 81 652-656

[43] 24 R. Hancock 2020 Muslim environmentalists, activism, and religious duty In Muslim Volunteering in the West. Palgrave Macmillan, Cham. 141-160

[44] H. Sugito, A. Khumaeni, \& Q. M. Binu 2020 Detection of heavy metal containment of soil pollution due to waste of paper industry using Nd: YAG laser induced breakdown spectroscopy In Journal of Physics: Conference Series. IOP Publishing. 14281012006

[45] M. A. Bhat, A. W. Adil, B. M. Sikander, Y. Lone, \& J. A. Malik 2020 Waste management technology for sustainable agriculture: Waste management In Innovative Waste Management Technologies for Sustainable Development. IGI Global. 156-176

[46] A. Garrigou, C. Laurent, A. Berthet, C. Colosio, N. Jas, V. Daubas-Letourneux, \& P. Lebailly 2020 Critical review of the role of PPE in the prevention of risks related to agricultural pesticide use Safety Science. 123104527

[47] J. Sullivan, B. Parras, R. S. Marie, W. Subra, S. Petronella, J. Gorenstein, \& P. Diamond 2020 Public talks and science listens: A community-based participatory approach to characterizing environmental health risk perceptions and assessing recovery needs in the wake of Hurricanes Katrina and Rita Environmental Health Insights. 31

[48] L. Fang, \& C. Tian 2020 Construction land quotas as a tool for managing urban expansion Landscape and Urban Planning. 195103727

[49] P. Chowdhary, R. N. Bharagava, S. Mishra, \& K. Khan 2020 Role of industries in water scarcity and its adverse effects on environment and human health. In Environmental Concerns and Sustainable Development. Springer, Singapore. 235-256

[50] K. Chandrasegaran, C. Lahondère, L. E. Escobar, \& C. Vinauger 2020 Linking mosquito ecology, traits, behavior, and disease transmission Trends in Parasitology.

[51] X. He, \& P. Li 2020 Surface water pollution in the middle Chinese Loess Plateau with special focus on hexavalent chromium $(\mathrm{Cr} 6+)$ : occurrence, sources and health risks Exposure and Health. 1-17

[52] R. Qadri, \& M. A. Faiq 2020 Freshwater pollution: Effects on aquatic life and human health In Fresh Water Pollution Dynamics and Remediation. Springer, Singapore. 15-26

[53] J. O. Klompmaker, G. Hoek, L. D. Bloemsma, M. Marra, A. H. Wijga, C. van den Brink, \& N. A. Janssen 2020 Surrounding green, air pollution, traffic noise exposure and non-accidental and cause-specific mortality Environment International. 134105341

[54] J. E. D. Cordova, V. T. Aguirre, V. V. Apestegui, L. O. Ibarguen, B. N. Vu, K. Steenland, \& G. F. G. Rengifo 2020 Association of PM 2.5 concentration with health center outpatient visits for respiratory diseases of children under 5 years old in Lima, Peru Environmental Health. 19 1 1-6

[55] A. Stenke 2020 Natural control on ozone pollution Nature Climate Change. 102 101-102 